\title{
The Protection of The Right to Health Services for The People With mental Disorders Especially in Yogyakarta Based on Law Number 18 of 2014 Mental Health
}

\author{
Perlindungan Hak Atas Pelayanan Kesehatan Bagi Orang Dengan Gangguan Jiwa Di Daerah \\ Istimewa Yogyakarta Berdasarkan Undang Undang Nomor 18 Tahun 2014tentang \\ Kesehatan Jiwa \\ Odilia Esem, Dr. Endang Wahyati, Tjahjono Kuntjoro \\ email: odilia.esem@yahoo.com
}

Health Law Master Program, Soegijapranata Catholic University of Semarang

\begin{abstract}
The rights to health care were basic rights that were subjected to every person, including people having mental disorders (ODGJ). The ODGJ had the same opportunity to get health services through the mental health facilities, mental health workers, mental health supplies provided by the government. This study aimed to know the regulation on ODGJ's health service rights, the implementation of the protection of ODGJ's rights to health services and the factors affecting the implementation of the protection of ODGJ's rights to health services. The research was conducted at the Special Province of Yogyakarta (DIY) namely in Grhasia Mental Hospital, Panembahan Senopati General Hospital of Bantul and Mergangsan Public Health Center. This research applied a socio-legal approach having an analyticaldescriptive specification. The data gathered were primary and secondary data that were obtained by field studies and literature study. The field studies were conducted by interviews with the directors of the hospitals, Head of the Public Health Center, Head of Health Office, and ODGJ'sfamilies. The data were then qualitatively analyzed. The results of the study showed that there had been provisions ODGJ's rights to health services based on the Republic of Indonesia's Constitution, Act Nr. 39 of 1999 on Human Rights, Act Nr. 36 of 2009 on Health, Act Nr.18 of 2014 on Mental Health, Minister of Health's Regulation Nr. 43 of 2016 on Minimum Service Standard in Health Sector, Yogyakarta Special Province's Regulation Nr. 1 of 2014 on Vagrant and Beggars and Yogyakarta Governor's Regulation Nr. 81 of 2014 on Guidance for Stocks Placement Prevention. Health services for ODGJ had been accomplished in Yogyakarta Province by providing health facilities at both the hospitals and the public health center as well. However, the protection of ODGJ'srights to health services had not been optimally fulfilled. It was influenced by several factors namely juridical, social and technical factors.
\end{abstract}

Keywords: rights protection, mental health service, people with mental disorders 


\section{PENDAHULUAN}

Hak asasi manusia adalah hak-hak dasar yang melekat pada diri manusia secara kodrati, universal dan langgeng sebagai anugerah Tuhan Yang Maha Esa. ${ }^{1}$ Hak dasar pertama adalah hak untuk hidup yang membawa konsekuensi adanya hak-hak lain termasuk hak atas pelayanan kesehatan. Pelayanan kesehatan sebagai kumpulan sarana dan prasarana guna melindungi, menunjang dan meningkatkan kesehatan manusia yang merupakan salah satu bentuk perlindungan hukum dan mendapatkan perhatian yuridis. ${ }^{2}$ Di dalam Pasal $28 \mathrm{H}$ ayat (1) Undang-Undang Dasar Tahun 1945 disebutkan bahwa, "Setiap orang berhak hidup sejahtera lahir dan batin, bertempat tinggal, dan mendapatkan lingkungan hidup yang baik dan sehat serta berhak memperoleh pelayanan kesehatan." Hak atas pelayanan kesehatan merupakan hak dasar yang harus dipenuhi oleh pemerintah tanpa diskriminasi terhadap setiap orang termasuk Orang Dengan Gangguan Jiwa.Gangguan jiwa adalah sindrom atau pola perilaku, atau psikologik seseorang, yang secara klinik cukup bermakna dan yang secara khas berkaitan dengan suatu gejala penderitaan (distress) atau hendaya (impairment/disability) di dalam satu atau lebih fungsi yang penting dari manusia. ${ }^{3}$

Berdasarkan data Riset Kesehatan Dasar tahun 2013 (Riskesdas) di Indonesia menunjukan prevalensi gangguan jiwa mencapai sekitar 400.000 orang atau sebanyak 1,7 per 1000 penduduk. Prevalensi jumlah gangguan jiwa tertinggi berada di Dareah Istimewa Yogyakarta. Total jumlah penderita gangguan jiwa di DIY diperkirakan mencapai 9.862 orang. ${ }^{4} J u m l a h$ ODGJ terbanyak berada di wilayah Kabupaten Bantul yaitu 3875 orang (39,29\%), Kulonprogo mencapai 1892 orang (19,18\%), Gunung Kidul mencapai 1433 orang $(14,53 \%)$, Sleman mencapai 1769 orang (17,94\%), dan jumlah ODGJ yang paling sedikit berada di wilayah Kota Yogyakarta yaitu 857 orang $(8,68 \%) .{ }^{5}$ Penyebab tingginya jumlah ODGJ di DIY adalah karena faktor bancana alam yang terjadi di DIY, khususnya Kabupaten Bantul dan Kabupaten Kulonprogo sebagai wilayah yang sering terjadi bencana alam yaitu gempa bumi dan banjir. Selain itu tingginya jumlah ODGJ juga disebabkan oleh beberapa hal diantaranya adalah gaya hidup, budaya, lahan pekerjaan yang tidak memadai untuk menampung lulusan sekolah dan perguruan tinggi yang kian terus bertambah, hal ini menjadi salah satu kontributor yang memicu terjadinya stress atau gangguan jiwa di DIY.

Daerah Istimewa Yogyakarta hanya ada 1 Rumah Sakit Jiwa untuk lima Kabupaten. Sehingga pelayanan kesehatan pada ODGJ hanya ditangani oleh satu Rumah Sakit tersebut, sementara fasilitas pelayanan kesehatan lain belum semuanya menyediakan layanan kesehatan jiwa. Pelayanan kesehatan jiwa sebagian besar masih diberikan oleh dokter umum dan hanya sebagian kecil yang ditangani oleh dokter spesialis kesehatan jiwa. Hal ini terjadi karena kurangnya jumlah tenaga khusus kesehatan jiwa. Kendala dalamlayanan non medis antara lain tidak tersebarnya tenaga non medis secara merata diseluruh daerah. ${ }^{6}$

Kondisi ini jelas tidak memberikan keadilan bagi ODGJ. Sebagai warga negara ODGJ memiliki hak yang sama seperti masyarakat pada umumnya. ODGJ berhak atas hidup yang

\footnotetext{
'Bahder Johan Nasution, 2011, Negara Hukum dan Hak Asasi Manusia, Bandung: Mandar Maju

${ }^{2}$ Fredy Tengker, 2007, Hak Pasien, Bandung: Mandar Maju

${ }^{3}$ Maslim Rusdi, 2013, Diagnosis Gangguan Jiwa: Rujukan Ringkas PPDGJ-III Dan DSM-5, Jakarta: Bagian Ilmu Kedokteran Jiwa FK-Unika Atmajaya

${ }^{4}$ Balitbang Kesehatan, 2013, Laporan Riset Kesehatan Dasar, Jakarta: Kementerian Kesehatan Republik Indonesia

${ }^{5}$ Dinas Kesehatan Provinsi Daerah Istimewa Yogyakarta, 2016, Data Kesehatan Jiwa Daerah Istimewa Yogyakarta

${ }^{6}$ Yosep Adi Prasetyo, Mewujudkan Pemenuhan HAM ODMK, 2009, Jurnal HAM Komisi Nasional Hak Asasi Manusia, Vol. 6, No. 26
} 
membawa konsekuensi adanya hak-hak lain termasuk hak atas pelayanan kesehatan. Apabila hak atas pelayanan kesehatan bagi ODGJ terpenuhi, maka ODGJ dapat kembali menjadi sehat baik secara fisik maupun jiwa. Sehingga ODGJ dapat hidup setara dengan masyarakat pada umumnya, dan dapat berkarya untuk memberikan kontribusi sesuai dengan kemampuannya masing-masing di dalam kehidupan masyarakat. Maka dari itu, negara sebagai pemangku kewajiban hak asasi manusia harus melaksanakan kewajiban dalam memberikan perlindungan hukum terhadap ODGJ.

Menurut Satjipto Rahardjo, perlindungan hukum adalah memberikan pengayoman terhadap hak asasi manusai (HAM) yang dirugikan oleh orang lain dan perlindungan itu diberikan kepada masyarakat agar dapat menikmati semua hak-hak yang diberikan oleh hukum. ${ }^{7}$ Sesuai pengertian perlindungan hukum tersebut, maka suatu perlindungan hukum harus diberikan oleh pemerintah terhadap ODGJ dalam bentuk peraturan dan kebijakan tentang kesehatan yang harus direalisasikan di lapangan, yaitu melalui penyediaan fasilitas pelayanan kesehatan jiwa bagi ODGJ, penyediaan tenaga kesehatan jiwa serta perbekalan kesehatan jiwa yang memadai. Sehingga dapat memberikan suatu keadilan bagi seluruh masyarakat tanpa terkecuali termasuk bagi ODGJ dalam pemenuhan perlindungan hak atas pelayanan kesehatannya.

Rumah Sakit merupakan sebuah institusi besar, sebuah lembaga yang rumit, lembaga yang membutuhkan sarana prasarana dan dana yang besar, tempat (fisik), untuk melakukan kegiatan yang menggunakan peralatan berteknologi canggih, dimana orang sakit mendapatkan perawatan, sebagai tempat bertemunya para profesional yang melakukan praktik profesi, pendidikan dan pelatihan para calon tenaga medis dan tenaga kesehatan juga merupakan tempat penelitian dan kegiatan pengembangan ilmiah di bidang kesehatan, sebagai organisasi yang kompleks, membutuhkan SDM yang banyak, memiliki misi sosial dan kemanusiaan, diatur dalam seperangkat perundang-undangan dilengkapi regulasi pelaksanaan, sebagai sebuah sistem yang dinamis dan adaptif, karena harus berinteraksi terus menerus dengan lingkungan eksternal, sosial dan lingkungan organisasi." 8

Berdasarkan jenis pelayanan yang diberikan, Rumah Sakit dikelompokan dalam rumah Sakit Umum dan Rumah Sakit Khusus.Rumah Sakit Umum adalah rumah sakit yang menyelenggarakan pelayanan kesehatan kepada masyarakat untuk semua jenis penyakit, mulai dari pelayanan kesehatan dasar sampai dengan pelayanan subspesialistik sesuai dengan kemampuannya.Rumah Sakit Khusus adalah rumah sakit yang menyelenggarakan pelayanan kesehatan kepada masyarakat untuk jenis penyakit atau berdasarkan disiplin ilmu tertentu. ${ }^{9}$ Rumah Sakit sebagai salah satu bentuk fasilitas pelayanan kesehatan harus menyediakan pelayanan kesehatan yang memadai untuk meningkatkan derajat kesehatan setiap orang termasuk menyediakan pelayanan kesehatan jiwa. Perlindungan hak pelayanan kesehatan bagi ODGJ tidak hanya diberikan melalui penyelenggaraan pelayanan kesehatan jiwa di Rumah Sakit Khusus Kesehatan Jiwa tetapi juga harus diselenggarakan di fasilitas pelayanan kesehatan umum lainnya.

\footnotetext{
${ }^{7}$ Satjipto Rahardjo, 2000, Ilmu Hukum, Bandung: PT. Citra Aditya Bakti

${ }^{8}$ Endang Wahyati Yustina, 2012, Mengenal Hukum Rumah Sakit, Bandung: Keni Media

${ }^{9}$ Bambang Hartono, 2010, Promosi Kesehatan di Puskesmas dan Rumah Sakit, Jakarta: Rineka Cipta
} 
Berdasarkan problematika di atas maka peneliti tertarik untuk meneliti tentang "Perlindungan Hak Atas Pelayanan Kesehatan Bagi Orang Dengan Gangguan Jiwa Di Daerah Istimewa Yogyakarta Berdasarkan Undang-Undang Nomor 18 Tahun 2014 Tentang Kesehatan Jiwa." Penelitian ini dibatasi pada penyediaan pelayanan kesehatan jiwa difasilitas kesehatan, baik fasilitas kesehatan khusus jiwa maupun fasilitas kesehatan umum lainnya dan mendapatkan penanganan oleh tenaga yang memiliki kualifikasi dalam bidang kesehatan jiwa serta penyediaan perbekalan kesehatan jiwa bagi ODGJ. Hal ini didukung oleh masih banyaknya ODGJ yang belum mendapatkan haknya dalam memperoleh pelayanan kesehatan. Penelitian dilakukan dengan tujuan melakukan kajian pada pelaksanaan pelayanan kesehatan bagi ODGJ dan perlindungan hak atas pelayanan kesehatan bagi ODGJ baik itu dari segi pengaturan perlindungan hak pelayanan kesehatan ODGJ, pelaksanaan perlindungan hak pelayanan kesehatan serta faktor-faktor yang mempengaruhi pelaksanaan perlindungan hak pelayanan kesehatan. Adapun manfaat dari penelitian ini adalah dapat memberikan masukan kepada Pemerintah khususnya Pemerintah DIY dalam memberikan perlindungan hak atas pelayanan kesehatan bagi ODGJ dan dapat memberikan pemahaman serta pengetahuan terhadap masyarakat untuk tidak melakukan stigma dan menerima kembali ODGJ dalam kehidupan masyarakat.

\section{PERUMUSAN MASALAH}

Rumusan masalah pada penelitian ini adalah :

1. Bagaimana pengaturan tentang hak atas pelayanan kesehatan bagi orang dengan gangguan jiwa?

2. Bagaimana pelaksanaan perlindungan hak pelayanan kesehatan bagi orang dengan gangguan jiwa di DIY?

3. Apakah faktor-faktor yang mempengaruhi pelaksanaan perlindungan hak pelayanan kesehatan orang dengan gangguan jiwa di DIY?

\section{METODE PENELITIAN}

Penelitian dilakukan di Daerah Istimewa Yogyakarta.Penelitian ini menggunakan metode pendekatan yuridis sosiologis dengan spesifikasi penelitian deskriptif analitik.Desain penelitian yang digunakan dalam bentuk tek kalimat atau narasi.Penelitian ini menggunakan data primer dan data sekunder dimana pengumpulan data dilakukan melalui studi lapangan dan studi kepustakaan. Adapun dalam pengambilan sampel menggunakan teknik purposive sampling yaitu teknik pengambilan sampel yang dilakukan dengan memilih satuan sampling atas dasar pertimbangan tertentu atau pertimbangan sekelompok pakar di bidang ilmu yang sedang diteliti.Maka sampel dalam penelitian ini adalah tiga fasilitas pelayanan kesehatan yang melakukan pelayanan kesehatan jiwa pada ODGJ di Daerah Istimewa Yogyakarta, yaitu Rumah Sakit Jiwa Grhasia, Rumah Sakit Umum Daerah Panembahan Senopati Bantul dan Puskesmas Mergangsan Kota Yogyakarta. Analisis data yang digunakan adalah analisis data kualitatif. 


\section{PEMBAHASAN}

1. Pengaturan Perlindungan Hak Pelayanan Kesehatan Bagi ODGJ

a. Dasar Hukum Perlindungan Hak Atas Pelayanan Kesehatan ODGJ

Dasar hukum merupakan ketentuan dalam peraturan perundang-undangan yang menjadi landasan bagi setiap penyelenggaraan atau tindakan hukum oleh subyek hukum. Adapun dasar hukum pengaturan perlindungan hak atas pelayanan kesehatan bagi ODGJ antara lain :

1. Undang-Undang Dasar Negara Republik Indonesia Tahun 1945 (UUD 1945)

2. UUD 1945 dengan jelas mengatur adanya hak atas pelayanan kesehatan bagi masyarakat. Dimana tujuannya adalah untuk memberikan jaminan pada setiap orang agar mendapatkan kehidupan yang baik dan sehat serta memperoleh pelayanan kesehatan yang ditujukan tanpa ada batasan kepada siapapun bagi seluruh masyarakat Indonesia tanpa terkecuali termasuk bagi ODGJ.

3. Undang-Undang Nomor 39 Tahun 1999 Tentang Hak Asasi Manusia

4. Undan-Undang Nomor 39 Tahun 1999 pada intinya mengatur tentang perlindungan hak asasi manusia termasuk hak bagi ODGJ dalam mendapatkan pelayanan kesehatan. Hak atas pelayanan kesehatan merupakan salah satu bentuk hak asasi manusia. Oleh karena itu hak pelayanan kesehatan sebagai hak yang melekat pada setiap orang tanpa terkecuali. ODGJ mempunyai hak yang sama sebagaimana masyarakat pada umumnya dalam memperoleh pelayanan kesehatan sebagai hak asasi ODGJ. Hak asasi manusia harus dihormati dan dilindungi oleh setiap orang termasuk hukum dan pemerintah.

5. Undang-Undang Nomor 36 Tahun 2009 Tentang Kesehatan

6. Inti pengaturan dari Undang-Undang Nomor 36 Tahun 2009 Tentang kesehatan adalah hak hidup sehat bagi semua orang termasuk bagi ODGJ. Artinya bahwa ODGJ juga memiliki kesempatan yang sama untuk memperoleh pelayanan kesehatan jiwa. Hak atas kesehatan yang dimaksud dalam ketentuan tersebut adalah hak untuk memperoleh pelayanan kesehatan di fasilitas kesehatan agar dapat mewujudkan derajat kesehatan yang setinggi-tingginya.Untuk itu Pemerintah bertanggung jawab dalam memenuhi hak atas pelayanan kesehatan tersebut melalui penyelenggaraan pelayanan kesehatan.

7. Undang-Undang Nomor 18 Tahun 2014 Tentang Kesehatan Jiwa

8. Inti pengaturan dari Undang-Undang Nomor 18 Tahun 2014 Tentang Kesehatan Jiwa yaitu untuk menjamin setiap orang dapat mencapai kualitas hidup yang baik, menikmati kehidupan kejiwaan yang sehat, bebas dari ketakutan, tekanan, dan gangguan lain yang dapat mengganggu Kesehatan Jiwa, menjamin setiap orang dapat mengembangkan potensi kecerdasan, memberikan pelindungan dan menjamin pelayanan Kesehatan Jiwa bagi ODGJ berdasarkan hak asasi manusia, memberikan pelayanan kesehatan secara terintegrasi, komprehensif, dan berkesinambungan melalui upaya promotif, preventif, kuratif, dan rehabilitatif, menjamin ketersediaan dan keterjangkauan sumber daya dalam Upaya Kesehatan Jiwa, meningkatkan mutu Upaya Kesehatan Jiwa sesuai dengan perkembangan ilmu pengetahuan dan teknologi, dan memberikan kesempatan kepada ODGJ untuk dapat melaksanakan hak dan kewajibannya sebagai Warga Negara Indonesia. 


\section{b. Bentuk Pengaturan Perlindungan Hak Atas Pelayanan Kesehatan ODGJ}

Bentuk pengaturan perlindungan hak atas pelayanan kesehatan bagi ODGJ di DIY didasarkan pada ketentuan pengaturan Undang-Undang yang menjadi dasar hukum perlindungan hak pelayanan kesehatan ODGJ. Adapun bentuk pengaturan perlindungan hak pelayanan kesehatan ODGJ di DIY antara lain :

1. Peraturan Menteri Kesehatan Nomor 43 Tahun 2016 Tentang Standar Pelayanan Minimal Bidang Kesehatan.

2. Standar pelayanan minimal bidang kesehatan sebagai ketentuan yang mengatur jenis dan mutu pelayanan bidang kesehatan dasar yang merupakan urusan pemerintahan wajib yang berhak diperoleh setiap warga. Peraturan ini berfungsi untuk memfasilitasi Pemerintah Daerah dalam melakukan pelayanan bidang kesehatan yang tepat bagi masyarakat. Pemerintah Daerah melalui Dinas Kesehatan bertangggungjawab melaksanakan pelayanan kesehatan sesuai dengan SPM Bidang Kesehatan yang telah ditetapkan. Salah satu SPM Bidang Kesehatan yang dilakukan oleh Pemerintah Daerah yaitu menyelenggarakan pelayanan kesehatan sesuai standar bagi ODGJ melalui penyediaan fasilitas kesehatan, penyediaan tenaga khusus kesehatan jiwa serta penyediaan perbekalan kesehatan jiwa.

3. Peraturan Daerah Daerah Istimewa Yogyakarta Nomor 1 Tahun 2014 Tentang Penanganan Gelandangan Dan Pengemis.

4. Peraturan Daerah Istimewa Yogyakarta Nomor 1 Tahun 2014 Tentang Penanganan Gelandangan Dan Pengemis merupakan peraturan khusus yang memberikan perlindungan dan menjamin agar gelandangan dan pengemis mendapatkan kesejahteraan dan kehidupan yang layak termasuk gelandangan dan pengemis dengan gangguan psikotik. Dalam hal gelandangan dan pengemis berdasarkan hasil identifikasi diindikasikan mengalami gangguan jiwa dilakukan rehabilitasi kejiwaan yang dilaksanakan oleh Rumah Sakit Jiwa Grhasia dan Rumah Sakit lainnya yang bekerja sama dengan Pemerintah Daerah.

5. Peraturan Gubernur Daerah Istimewa Yogyakarta Nomor 81 Tahun 2014 Tentang Pedoman Penanggulangan Pemasungan

6. Peraturan Gubernur Daerah Istimewa Yogyakarta Nomor 81 Tahun 2014 Tentang Pedoman Penanggulangan Pemasungan merupakan peraturan yang dikeluarkan oleh Pemerintah DIY untuk memberikan perlindungan dan menjamin ODGJ dari tindakan pemasungan. Tindakan pemasungan merupakan salah satu bentuk pelanggaran hak yang mengakibatkan ODGJ tidak mendapatkan hak dalam memperoleh pelayanan kesehatan. Sasaran dalam peraturan ini tidak hanya ditujukan kepada ODGJ tetapi ditujukan juga kepada keluarga sebagai orang yang terlibat dalam membantu menangani ODGJ melalui pengetahun tentang kesehatan jiwa dan memberi dukungan sosial untuk upaya penyembuhan ODGJ. Sehingga pada akhirnya tindakan pemasungan yang dilakukan terhadap ODGJ dapat dihindari. 


\section{c. Tujuan Pengaturan Perlindungan Hak Atas Pelayanan Kesehatan ODGJ}

1. Pemerintah telah memberikan perlindungan terhadap hak pelayanan kesehatan ODGJ melalui penetapan ketentuan terkait ODGJ. Ketentuan tersebut menjadi dasar hukum dalam pembentukan pengaturan khusus tentang hak pelayanan kesehatan ODGJ yang harus dipenuhi. Adapun tujuan pembentukan pengaturan perlindungan hak pelayanan kesehatan bagi ODGJ antara lain :

2. Pengaturan tentang perlindungan hak pelayanan kesehatan ODGJ yang dituangkan dalam Peraturan Menteri Kesehatan Nomor 43 Tahun 2016 Tentang Standar Pelayanan Minimal Bidang Kesehatan, memiliki tujuan untuk melaksanakan amanat Undang-Undang Dasar Republik Indonesia Nomor 36 Tahun 2009 Tentang Kesehatanserta sebagai acuan bagi Pemerintah Daerah Kabupaten/Kota dalam penyediaan pelayanan kesehatan yang berhak diperoleh setiap warga secara minimal. Pemerintah mempunyai tanggung jawab untuk menjamin setiap warga memperoleh pelayanan kesehatan yang berkualitas sesuai dengan kebutuhan masing-masing. Salah satu pelayanan kesehatan yang wajib diselenggarakan yaitu pelayanan kesehatan jiwa bagi ODGJ.

3. Pengaturan tentang perlindungan hak atas pelayanan kesehatan ODGJ yang dituangkan dalam Peraturan Daerah Istimewa Yogyakarta Nomor 1 Tahun 2014 Tentang Penanganan Gelandangan Dan Pengemis, memiliki tujuan untukmelaksanakan ketentuan Pasal 149 Undang-Undang Nomor 36 Tahun 2009 Tentang Kesehatan sertamemberikan perlindungan dan menjamin gelandangan yang mempunyai gangguan jiwa dengan mengembalikan gelandangan yang mempunyai gangguan jiwa dalam kehidupan yang bermartabat melalui pelayanan kesehatan yang dapat membantu penyembuhan gelandangan yang mempunyai gangguan jiwa menjadi pribadi yang produktif untuk kehidupan pribadi, keluarga dan masyarakat.

4. Pengaturan tentang perlindungan hak atas pelayanan kesehatan ODGJ yang dituangkan dalam Peraturan Gubernur Daerah Istimewa Yogyakarta Nomor 81 Tahun 2014 Tentang Pedoman Penanggulangan Pemasungan, memiliki tujuan untuk melaksanakan ketentuan Undang-Undang Nomor 18 Tahun 2014 Tentang Kesehatan Jiwa mendukung upaya peningkatan derajat kesehatan jiwa masyarakat di wilayah Daerah Istimewa Yogyakarta serta memberikan panduan kepada pemangku kepentingan dalam upaya meningkatkan derajat kesehatan jiwa masyarakat.Sehingga dapat memberikan keadilan dan upaya pemenuhan dalam memperoleh hak atas pelayanan kesehatan ODGJ

2. Pelaksanaan Perlindungan Hak Atas Pelayanan Kesehatan Bagi ODGJ Di Daerha Istimewa Yogyakarta

a. Lembaga Yang Terkait Dalam Pelaksanaan Perlindungan Hak Atas Pelayanan Kesehatan Bagi ODGJ Di DIY

Dalam pelaksanaan perlindungan hak atas pelayanan kesehatan ODGJ di DIY melibatkan beberapa lembaga terkait yang mendukung upaya penyelenggaraannya, diantaranya adalah :

1. Dinas Kesehatan

ugas Dinas Kesehatan Daerah Istimewa Yogyakarta dalam bidang kesehatan jiwa secara khusus diatur dalam Peraturan Gubernur Daerah Istimewa Yogyakarta 
Nomor 81 Tahun 2014 Tentang Pedoman Penanggulangan Pemasungan. Dijelaskan bahwa tugas dan wewenang Dinas Kesehatan dalam bidang kesehatan jiwa yaitu memberikan layanan serta akses komunikasi, informasi dan edukasi yang benar kepada masyarakat tentang kesehatan jiwa, melaksanakan pembinaan sumber daya manusia dibidang Kesehatan Jiwa, menyediakan akses pelayanan yang berkesinambungan meliputi pengobatan, pemulihan psikososial, rehabilitasi, pendampingan, dan/atau dukungan lain yang memadai untuk ODGJ, menyediakan pengobatan dan perawatan ODGJ di Rumah Sakit Jiwa, Rumah Sakit, dan Puskesmas, meningkatkan jumlah puskesmas yang memberikan pelayanan kesehatan jiwa terutama untuk ODGJ.

2. Dinas Sosial

Dinas Sosial Daerah Istimewa Yogyakarta dalam melaksanakan tugasnya terhadap penanganan gelandangan dan pengemis yang mempunyai gangguan psikotik berdasarkan pada Peraturan Daerah Daerah Istimewa Yogyakarta Nomor 1 Tahun 2014 Tentang Gelandangan Dan Pengemis. Untuk penanganan gelandangan psikotik Dinas Sosial melakukan koordinasi dengan Dinas Kesehatan dan Rumah Sakit Jiwa Grhasia. Apabila dari hasil pemeriksaan menunjukan bahwa gelandangan tersebut mempunyai gangguan psikotik maka Dinas Sosial akan berkoordinasi dengan Rumah Sakit Jiwa Grhasia untuk pelaksanaan rujukan pasien tersebut ke Rumah Sakit Jiwa Grhasia agar mendapatkan perawatan kesehatan jiwa yang lebih sesuai dalam bidang kesehatan jiwa.

3. Rumah Sakit

Rumah Sakit berperan untuk memberikan pelayanan kesehatan secara paripurna, menyelenggarakan pelayanan pengobatan dan pemulihan kesehatan sesuai dengan standar pelayanan Rumah Sakit, pemeliharaan dan peningkatan kesehatan perorangan melalui pelayanan kesehatan yang paripurna tingkat kedua dan ketiga sesuai kebutuhan medis, menyelenggarakan pendidikan dan pelatihan sumber daya manusia dalam rangka peningkatan kemampuan dalam pemberian pelayanan kesehatan.

4. Puskesmas

Tugas dan kewenangan Puskesmas dalam pelayanan kesehatan jiwa adalah menyelenggarakan Pelayanan promotif, preventif yang bertujuan meningkatkan kesehatan jiwa ODGJ dan mencegah terjadinya kekambuhan. Pelayanan promotif kesehatan jiwa pada ODGJ meliputi edukasi dan evaluasi tentang tanda dan gejala gangguan jiwa, kepatuhan minum obat dan informasi lain terkait kesehatan jiwa. Pelayanan kesehatan jiwa pada ODGJ di Puskesmas diberikan oleh perawat dan dokter Puskesmas.

b. Mekanisme Pelaksanaan Perlindungan Hak Atas Pelayanan Kesehatan Bagi ODGJ Di Daerah Istimewa Yogyakarta

1. Pembentukan Tim

Pelaksanaan pelayanan kesehatan ODGJ di Daerah Istimewa Yogyakarta melibatkan beberapa tim yang dibentuk oleh Pemerintah Daerah untuk mendukung upaya program kesehatan jiwa. Adapun tim yang yang mendukung pelaksanaan pelayanan kesehatan jiwa antara lain: 
a. Tim Pengarah Kesehatan Jiwa Masyarakat

Tim pengarah kesehatan jiwa masyarakat atau yang disingkat dengan TPKJM merupakan tim yang memberikan pengarahan dan pelaksanaan programprogram kesehatan jiwa masyarakat di tingkat Provinsi dan Kabupaten/Kota Daerah Istimewa Yogyakarta. Dalam beberapa tahun terakhir TPKJM dalam pelaksanaannya dapat dikatakan tidak aktif. Informan menambahkan hal tersebut terjadi karena tidak adanya pendanaan dari pemda untuk menjalankan kembali program tersebut.

b. Tim Kesehatan Jiwa Layanan Primer

Tim Kesehatan Jiwa Layanan Primer merupakan tim dari tenaga kesehatan yang terdiri atas dokter, psikolog, perawat, dan aptoteker di Puskesmas yang memiliki pengetahuan dan keterampilan khusus kesehatan jiwa melalui pendidikan profesional maupun pelatihan kesehatan jiwa untuk memberikan pelayanan kesehatan jiwa di Puskesmas yang meliputi pelayanan kesehatan jiwa promotif, preventif dan pelayanan kesehatan jiwa lainnya. Dari hasil wawancara dengan informan menyatakan bahwa semua Puskesmas di DIY telah mempunyai tim kesehatan jiwa layanan primer untuk menangani masalah kesehatan jiwa yang terjadi di wilayah Puskesmas.

c. Tim Transport

Tim transport merupakan kepanjangan tangan dari Dinas Kesehatan DIY yang melibatkan Dinas Kesehatan Provinsi, Dinas Kesehatan Kabupaten/Kota, RSUD, Puskesmas, Institusi Pendidikan yang mempunyai psikolog. Tim ini bertugas untuk menjangkau masalah kesehatan jiwa berat seperti pemasungan ODGJ dan masalah kesehatan jiwa lainnya.

2. Penyusunan Kebijakan

DIY telah mempunyai kebijakan yang mengatur terkait kesehatan jiwa yaitu Peraturan Gubernur Daerah Istimewa Yogyakarta Nomor 81 Tahun 2014 Tentang Pedoman Penanggulangan Pemasungan dan Peraturan Daerah Daerah Istimewa Yogyakarta Nomor 1 Tahun 2014 Tentang Gelandangan dan Pengemis. Dalam peraturan ini hanya mengatur gelandangan psikotik atau ODGJ yang terlantar untuk mendapatkan perawatan kesehatan jiwa di fasilitas kesehatan. Namun demikian, peraturan terkait kesehatan jiwa yang telah ada di DIY tersebut belum sepenuhnya mengatur hak pelayanan kesehatan ODGJ secara keseluruhan terutama hak pelayanan kesehatan difasilitas kesehatan.

3. Pelaksanaan di Failitas Kesehatan

a Rumah Sakit Jiwa Grhasia

Dalam melaksanakan pelayanan kesehatan jiwa Rumah Sakit Jiwa Grhasia menyediakan pelayanan kesehatan jiwa yang lengkap meliputi pelayanan kesehatan gawat darurat, pelayanan kesehatan jiwa rawat jalan, pelayanan kesehatan jiwa rawat inap, pelayanan psikologis, rehabilitasi kesehatan jiwa serta pelayanan penunjang kesehatan jiwa lainnya. Penanganan kesehatan pada ODGJ di Rumah Sakit Jiwa Grhasia dilakukan oleh dokter spesialis jiwa, dokter umum, perawat yang sudah mendapatkan pelatihan kesehatan jiwa dan tenaga profesional lainnya seperti psikolog. Rumah Sakit Jiwa Grhasia sudah memiliki tenaga psikiater yang berjumlah delapan orang. Selain itu untuk dokter umum yang sudah mendapatkan pelatihan kesehatan jiwa berjumlah 11 
orang dan tenaga profesional lainnya seperti psikolog berjumlah tiga orang. Untuk pemenuhan tenaga kesehatan lainnya sebagai penunjang tenaga kesehatan jiwa berjumlah lima orang dengan rincian spesialis anak satu orang, spesialis penyakit dalam satu orang, rehabilitasi medis satu orang, tenaga radiologi satu orang dan spesialis patologi klinik satu orang. Sedangkan untuk tenaga perawat sebanyak 122 orang.Namun demikian pemenuhan tenaga kesehatan tersebut belum dapat dikatakan optimal dibandingkan dengan jumlah pasien ODGJ yang banyak di Rumah Sakit Jiwa Grhasia. Selain itu Rumah Sakit Jiwa Grhasia juga sebagai fasilitas pelayanan kesehatan yang bekerjasama dengan Pemerintah Daerah yaitu Dinas Sosial untuk penanganan gelandangan psikotik.

b Rumah Sakit Umum Daerah Panembahan Senopati Bantul

Berdasarkan hasil penelitian Rumah Ssakit Umum Daerah Panembahan Senopati Bantul telah menyelenggarakan pelayanan kesehatan jiwa. Jenis pelayanan kesehatan jiwa yang diberikan merupakan pelayanan kesehatan jiwa rawat jalan. Penanganan kesehatan pada ODGJ di RSUD Panembahan Senopati Bantul dilakukan oleh dokter spesialis jiwa yang berjumlah satu orang dan perawat umum yang telah mendapatkan pelatihan tentang kesehatan jiwa berjumlah satu orang. Dari segi pemenuhan tenaga kesehatan jiwa di Rumah Sakit Jiwa Grhasia telah sesuai dengan ketentuan tentang klasifikasi dan perijinan Rumah Sakit Umum Tipe B yang mewajibkan Rumah Sakit Umum tipeB harus memiliki tenaga spesialis jiwa sebanyak satu orang. Namun demikian untuk menangani jumlah ODGJ yang banyak maka pemenuhan tenaga kesehatan jiwa tersebut belum dapat dikatakan optimal.

c Puskesmas Mergangsan

Puskesmas Mergangsan telah menyediakan pelayanan kesehatan jiwa bagi ODGJ. Pelayanan kesehatan jiwa yang diberikan oleh Puskesmas Mergangsan meliputi pengobatan ODGJ lepas rawat Rumah Sakit, menyediakan rawat jalan bagi ODGJ, penerimaan pasien ODGJ baru, mengadakan penyuluhan dan pertemuan dengan keluarga ODGJ dan rujukan ODGJ ke Rumah Sakit Jiwa.Pelayanan kesehatan pada ODGJ dilakukan oleh dokter umum dan perawat Puskemas yang telah mendapatkan pelatihan tentang kesehatan jiwa. Adapun tenaga kesehatan yang telah mendapatkan pelatihan jiwa yaitu satu orang dan perawat satu orang. Namun demikian untuk menangani jumlah ODGJ yang banyak maka pemenuhan tenaga kesehatan jiwa tersebut belum dapat dikatakan optimal.

Pemenuhan hak pelayanan kesehatan ODGJ dalam pelaksanaan di fasilitas kesehatan telah sesuai dengan ketentuan yang berlaku. DIY telah mempunyai Rumah Sakit Khusus Kesehatan Jiwa yaitu Rumah Sakit Jiwa Grhasia. Selain itu pelayanan kesehatan ODGJ juga telah diselenggarakan di fasilitas kesehatan umum lainnya seperti RSUD Panembahan Senopati Bantul dan Puskesmas Mergangsan. Di DIY telah tersedia berbagai jenis obat psikotropik yang tercantum dalam daftar obat esensial. Tetapi pendistribusian obat tersebut tidak merata diseluruh fasilitas kesehatan, sehingga masih ada Puskesmas yang mengalami kekurangan dalam perbekalan kesehatan jiwa. Hal ini menunjukan perlindungan hak pelayanan kesehatan ODGJ dalam pelaksanaan difasilitas kesehatan di DIY 
belum sepenuhnya sesuai dengan ketentuan yang berlaku dan teori perlindungan hukum yang menyatakan bahwa perlindungan hukum diberikan kepada masyarakat agar dapat menikmati semua hak-hak yang diberikan oleh hukum termasuk hak untuk memperoleh pelayanan kesehatan.

4 Pengembangan Sumber Daya Manusia

Tenaga kesehatan di DIY khususnya di Rumah Sakit Jiwa Grhasia, Rumah Sakit Umum Daerah Panembahan Senopati Bantul dan Puskesmas Mergangsan telah mendapatkan pelatihan kesehatan jiwa. Kegiatan pelatihan diadakan oleh pemerintah daerah untuk menanggulangi kekurangan tenaga kesehatan jiwa di DIY.

5 Pengawasan Dan Evaluasi

Pengawasan pelaksanaan pelayanan kesehatan ODGJ di fasilitas kesehatan melalui Dinas Kesehatan Provinsi, Dinas Sosial bersama-sama Dinas Kesehatan Kabupaten/Kota melakukan kegiatan supervisi difasilitas kesehatan untuk mengetahui pelaksanaan pelayanan kesehatan jiwa ODGJ difasilitas kesehatan. Dalam melaksanakan kegiatan supervisi menggunakan instrument baku. Pada pelaksanaannya kegiatan pengawasan dan evaluasi tidak dilakukan secara berkala atau hanya sesekali saja.

6 Pencatatan Dan Pelaporan

Pencatatan kejadian ODGJ dilakukan oleh tenaga kesehatan di fasilitas kesehatan dan melalui kunjungan rumah di tiap-tiap keluarga untuk mendeteksi anggota keluarga yang memiliki potensi gangguan jiwa atau mengalami gangguan jiwa. Untuk kegiatan pelaporan dilakukan oleh petugas kesehatan ke pihak yang berwenang setiap 3 bulan. Jika ada ODGJ yang tidak terlapor dihimbau untuk melapor ke fasilitas kesehatan sehingga kemudian dapat dilakukan pendataan.

\section{Faktor-Faktor Yang Mempengaruhi Pelaksanaan Perlindungan Hak Atas Pelayanan Kesehatan Jiwa Bagi ODGJ Di DIY}

a. Faktor Yuridis

1. Secara hukum belum ada peraturan khusus yang mengatur pelayanan kesehatan ODGJ di fasilitas kesehatan. Bentuk pengaturan yang sudah ada yaitu tentang pedoman penanggulangan pemasungan ODGJ dan Perda gelandangan psikotik. Sedangkan peraturan yang diperlukan adalah peraturan yang mengatur seluruh prosedur pelayanan kesehatan ODGJ di fasilitas kesehatan.

2. Belum ada standar operasional prosedur (SOP) khusus untuk penanganan pasien ODGJ di fasilitas kesehatan umum yaitu di Rumah Sakit Umum Daerah Panembahan Senopati Bantul dan di Puskesmas Mergangsan. Penanganan ODGJ masih menggunakan SOP pelayanan kesehatan pada umumnya. Akibatnya langkah penanganan ODGJ di fasilitas kesehatan tidak strategis.

b. Faktor Sosial

1. Masih banyak masyarakat yang melakukan stigma pada ODGJ. Masyarakat masih menganggap bahwa ODGJ merupakan akibat perbuatan roh jahat, ODGJ sebagai aib bagi keluarga, ODGJ sebagai orang yang berbahaya yang mengganggu kenyamanan dalam kehidupan di keluarga dan masyarakat. Sehingga untuk penanganannya masyarakat lebih memilih dilakukan oleh kaum rohanian serta 
dilakukan tindakan pemasungan ODGJ. Perlakukan dan stigma inilah yang sampai saat ini masih menyulitkan ODGJ untuk memperoleh pelayanan kesehatan di fasilitas kesehatan.

2. Berdasarkan hasil penelitian sebagian besar fasilitas kesehatan di DIY berpusat di Kota. Hal ini mengakibatkan kesulitan bagi ODGJ yang berada jauh dari pusat kota untuk mendapatkan akses ke fasilitas kesehatan. Sehingga keluarga cendrung membiarkan ODGJ begitu saja.

c. Faktor Teknis

1. Tim pengarah kesehatan jiwa masyarakat (TPKJM) yang dibentuk oleh Pemerintah DIY untuk membantu upaya penanganan ODGJ tidak berjalan sesuai dengan ketentuan yang berlaku. Dalam beberapa tahun terakhir TPKJM di DIY dapat dikatakan tidak aktif.

2. Pelayanan ODGJ di fasilitas kesehatan khususnya Puskesmas masih mengalami kekurangan dalam penyediaan perbekalan kesehatan jiwa seperti obat-obatan jiwa, peralatan kesehatan jiwa dan ambulan. Akibatnya untuk penanganan ODGJ yang mengalami keadaan darurat Puskesmas mengalami kesulitan melakukan penanganan dan merujuk ODGJ.

3. Jumlah tenaga kesehatan jiwa belum memadai sehingga penanganan ODGJ di fasilitas kesehatan sebagian besar masih dilakukan oleh tenaga kesehatan yang belum memiliki kualifikasi dalam bidang kesehatan jiwa seperti dokter umum dan perawat.

4. Tidak ada anggaran khusus terkait kesehatan jiwa dari Pemerintah Daerah.

\section{PENUTUP \\ KESIMPULAN}

Adapun kesimpulan yang dapat diambil dari penelitian ini adalah :

1. Pengaturan Tentang Perlindungan Hak Atas Pelayanan Kesehatan Bagi ODGJ

a. Peraturan perundang-undangan yang menjadi dasar hukum perlindungan hak pelayanan kesehatan ODGJ yaitu : Undang-Undang Dasar Republik Indonesia Tahun 1945, Undang-Undang Nomor 39 Tahun 1999 Tentang Hak Asasi Manusia, UndangUndang Nomor 36 Tahun 2009 Tentang Kesehatan, Undang-Undang Nomor 18 Tahun 2014 Tentang Kesehatan Jiwa.

b. Bentuk pengaturan perlindungan hak pelayanan kesehatan ODGJ di DIY yaitu Permenkes Nomor 42 Tahun 2016 Tentang Standar Pelayanan Minimal Bidang Kesehatan. Perda DIY Nomor 1 Tahun 2014 Tentang Penanganan Gelandangan Dan Pengemis. Pergub DIY Nomor 81 Tahun 2014 Tentang Pedoman Penanggulangan Pemasungan. Peraturan ini memberikan perlindungan dan jaminan pada ODGJ dari tindakan pemasungan yang merupakan salah satu bentuk tindakan yang menghalangi ODGJ untuk mendapatkan hak pelayanan kesehatan.

c. Tujuan pengaturan perlindungan hak atas pelayanan kesehatan ODGJ adalah untuk melaksanakan amanat peraturan perundang-undangan serta memberikan perlindungan dan menjamin pelayanan kesehatan jiwa bagi ODGJ berdasarkan hak asasi manusia dalam pelayanan kesehatan jiwa secara terintegrasi, komprehensif dan berkesinambungan melalui penyelenggaraan upaya pelayanan kesehatan jiwa bagi ODGJ. 
2. Pelaksanaan Perlindungan Hak Atas Pelayanan Kesehatan ODGJ Di Daerah Istimewa Yogyakarta

a. Lembaga Yang Terkait Dalam Pelaksanaan Perlindungan Hak Atas Pelayanan Kesehatan Bagi ODGJ Di DIY

Dalam melaksanakan pemenuhan hak pelayanan kesehatan ODGJ tidak bisa dilakukan oleh Rumah Sakit saja atau Dinas Kesehatan saja tetapi harus dilakukan melalui kerjasama antar lembaga terkait yang saling melengkapi satu sama lain sehingga hak pelayanan kesehatan ODGJ dapat terpenuhi secara maksimal, yaitu melibatkan Dinas Sosial, Rumah Sakit dan Puskesmas.

b. Mekanisme Pelaksanaan Perlindungan Hak Atas Pelayanan Kesehatan ODGJ Di DIY

Mekanisme pelaksanaan perlindungan hak atas pelayanan kesehatan ODGJ di DIY dilakukan dalam beberapa tahap yaitu melalui pembentukan tim, penyusunan kebijakan, pengembangan sumber daya manusia dan kemudian pelaksanaan pelayanan di fasilitas kesehatan baik di Rumah Sakit Jiwa, Rumah Sakit Umum dan Puskesmas.Pelayanan kesehatan jiwa difasilitas kesehatan sudah diberikan oleh tenaga kesehatan jiwa. Namun sebagian besar pelayanan kesehatan jiwa masih diberikan oleh tenaga kesehatan yang tidak memiliki kualifikasi dalam kesehatan jiwa, dan persediaan perbekalan kesehatan jiwa tidak merata diseluruh fasilitas kesehatan sehingga masih ada fasilitas kesehatan yang kekurangan perbekalan kesehatan jiwa.

3. Faktor-Faktor Yang Mempengaruhi Pelaksanaan Perlindungan Hak Atas Pelayanan Kesehatan Bagi ODGJ Di DIY.

Berdasarkan hasil penelitian dapat disimpulkan bahwa faktor-faktor yang mempengaruhi pelaksanaan perlindungan hak pelayanan kesehatan ODGJ berupa faktor yuridis, faktor sosial dan faktor teknis. Faktor-faktor tersebut ada yang mendukung dan menghambat pelaksanaan perlindungan pelayanan hak pelayanan kesehatan ODGJ.

\section{SARAN}

a. Pemerintah Perlu menyiapkan peraturan ditingkat daerah yang mengatur tentang kesehatan jiwa secara keseluruhan termasuk prosedur pelayanan kesehatan jiwa bagi ODGJ di fasilitas kesehatan.

b. Pemerintah harus menjadikan masalah kesehatan jiwa ODGJ sebagai salah satu isu kesehatan yang harus diprioritaskan sebagaimana isu kesehatan lainnya melalui penyediaan anggaran khusus untuk kesehatan jiwa ODGJ di Pemda DIY.

c. Pemerintah Perlu melaksanakan pembinaan dan pendidikan sumber daya manusia di bidang kesehatan jiwa dengan mengirim tenaga dokter atau perawat untuk melanjutkan pendidikan ke bidang khusus ilmu kesehatan jiwa baik psikiater maupun perawat jiwa.

d. Pemerintah Perlu menyediakan akses pelayanan yang berkesinambungan meliputi pengobatan, pemulihan psikososial, rehabilitasi, pendampingan atau dukungan lain yang memadai untuk ODGJ

e. Rumah Sakit perlu membuat kebijakan internal Rumah Sakit terkait pelayanan kesehatan ODGJ 
f. Rumah Sakit perlu menyelenggarakan pendidikan dan pelatihan tenaga kesehatan jiwa dalam rangka pemenuhan tenaga khusus kesehatan jiwa di Rumah Sakit serta dalam rangka meningkatkan kemampuan dalam pemberian pelayanan kesehatan oleh tenaga yang memiliki kualifikasi dalam bidang pelayanan kesehatan jiwa.

g. Masyarakat harus bekerjasama untuk mewujudkan perlindungan hak pelayanan kesehatan ODGJ dengan memberikan kesempatan pada ODGJ untuk melakukan perawatan di fasilitas kesehatan dengan cara membawa ODGJ ke fasilitas kesehatan.

h. Menerima kembali ODGJ yang telah pulih di dalam kehidupan masyarakat sehingga ODGJ dapat kembali menjadi pribadi yang produktif untuk kehidupan pribadi, keluarga dan masyarakat.

\section{DAFTAR PUSTAKA}

Bahder Johan Nasution, 2011, Negara Hukum dan Hak Asasi Manusia, Bandung: Mandar Maju

Bambang Hartono, 2010, Promosi Kesehatan di Puskesmas dan Rumah Sakit, Jakarta: Rineka Cipta

Balitbang Kesehatan, 2013, Laporan Riset Kesehatan Dasar, Jakarta: Kementerian Kesehatan Republik Indonesia

Dinas Kesehatan Provinsi Daerah Istimewa Yogyakarta, 2016, Data Kesehatan Jiwa Daerah Istimewa Yogyakarta

Endang Wahyati Yustina, 2012, Mengenal Hukum Rumah Sakit, Bandung: Keni Media

Fredy Tengker, 2007, Hak Pasien, Bandung: Mandar Maju

Maslim Rusdi, 2013, Diagnosis Gangguan Jiwa: Rujukan Ringkas PPDGJ-III Dan DSM-5, Jakarta: Bagian Ilmu Kedokteran Jiwa FK-Unika Atmajaya

Satjipto Rahardjo, 2000, Ilmu Hukum, Bandung: PT. Citra Aditya Bakti

Yosep Adi Prasetyo, Mewujudkan Pemenuhan HAM ODMK, 2009, Jurnal HAM Komisi Nasional Hak Asasi Manusia, Vol. 6, No. 26

Undang-Undang Dasar Tahun Republik Indonesia Tahun 1945

Undang-Undang Republik Indonesia Nomor 39 Tahun 1999 Tentang Hak Asasi Manusia

Undang-Undang Republik Indonesia Nomor 36 Tahun 2009 Tentang Kesehatan

Undang-Undang Republik Indonesia Nomor 18 Tahun 2014 Tentang Kesehatan Jiwa

Peraturan Menteri Kesehatan Nomor 46 Tahun 2016 Tentang Standar Pelayanan Minimal Bidang Kesehatan

Peraturan Daerah Daerah Istimewa Yogyakarta Nomor 1 Tahun 2014 Tentang Gelandangan Dan Pengemis

Peraturan Gubernur Daerah Istimewa Yogyakarta Nomor 81 Tahun 2014 Tentang Pedoman Penanggulangan Pemasungan 